\title{
Changes in the Indices of Refraction and Liquidus of a Barium Crown Glass Produced by the Partial Substitu- tion of Some Oxides ${ }^{1}$
}

\author{
By Edgar H. Hamilton, Oscar H. Grauer, Zeno Zabawsky, * and C. H. Hahner
}

\begin{abstract}
Optical glasses with high indices of refraction and Abbe values are very desirable for wide-angle lenses. In order to determine the range of compositions in which glasses of this type could be produced, oxides of $\mathrm{Li}, \mathrm{Be}, \mathrm{Ca}, \mathrm{B}$, La, or Th, were substituted for $\mathrm{BaO}$ or $\mathrm{SiO}_{2}$ in a three- or four-component base glass. Substitutions were made on a mole-for-mole basis. The indices of refraction for the $C, D, F$, and $G^{\prime}$ lines and the liquidus were determined for each glass. Experimental glasses with indices of refraction $\left(n_{D}\right)$ and Abbe values from 1.600 to 1.714 and 62.2 to 52.7 , respectively, were made in small platinum crucibles.
\end{abstract}

\section{Introduction}

Previous to 1880 , optical glasses could be divided into a few types such as crown, crown flint, and flint glasses with indices of refraction $(n)$ and Abbe value ( $\nu$ ) ranging from 1.50 to 1.92 and 70 to 20 , respectively. The $\nu$ value of the glasses decreased as the index of refraction increased so that, when $\nu$ is plotted against $n$, the points fall on a curved line. Abbe and Schott introduced a number of new types of glasses containing boron and barium oxides with $\nu$ values higher than for the old types of glasses with the same $n_{D}$. Recently G. W. Morey ${ }^{2}$ [1] developed a number of new glasses in which the ratio of Abbe value to index of retraction is much bigher than for the glasses of Abbe and Schott. This paper gives the composition, optical and other properties of some other glasses, which also have a high ratio of $\nu$ value to index of refraction. These glasses may find a use in optical instruments where a large flat field with a minimum of aberration is desired.

The oxides that gave promise of being useful in making such glasses were $\mathrm{B}_{2} \mathrm{O}_{3}, \mathrm{BeO}, \mathrm{CaO}, \mathrm{La}_{2} \mathrm{O}_{3}$, $\mathrm{ThO}_{2}$, and $\mathrm{Li}_{2} \mathrm{O}$. Although glasses containing such oxides have been described in the literature [1], few

\footnotetext{
*Now with the Armstrong Cork Co., Lancaster, Pa.

${ }_{1}$ Presented at the Forty-Eighth Annual Meeting, the American Ceramic Society, Buffalo, N. Y., May 1, 1946 (Glass Division No. 13).

2 Figures in brackets indicate the literature references at the end of the paper.
}

systematic data are available on the effect of these oxides on the range of compositions in which glass can be produced. In this investigation one of the above oxides was substituted on a mole-for-mole basis for part of the barium oxide or silica in a base glass containing the following:

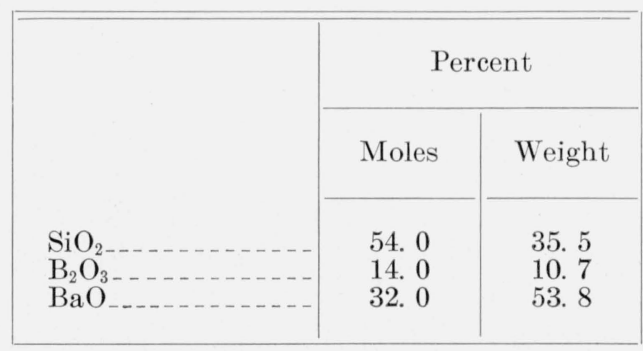

The substitutions were made in steps in order to determine the shapes of the index-of-refractioncomposition and liquidus-composition curves. When glasses with desirable properties resulted, these glasses were used as base glasses for further substitutions.

\section{Experimental Procedure}

All melts were made in platinum crucibles $90 \mathrm{~mm}$ deep by $36 \mathrm{~mm}$ in diameter and stirred with platinum-10-percent-rhodium stirrers. Although the melts were stirred, striae-free glass could consistently be obtained only by crushing, mixing, 
and remelting each glass. ${ }^{3}$ A few compositions required remelting a second time to obtain glasses sufficiently free from striae to permit reliable index of refraction measurements to be made.

The presence of striae in optical glass is a very serious obstacle to the production of useful glasses. As the striae consist of local inhomogeneities in composition, any measurement on the glass that includes striae will be different in general from measurements on the rest of the glass. Even the portion of the glass that does not contain striae will have a different composition, because the striae will have removed disproportionate amounts of its constituents.

Furthermore, on annealing the glass, differences in the coefficients of expansion between the glass and striae will cause local strains and thus give rise to differences in index of refraction for different parts of the glass.

Striae have always "haunted" the optical-glass maker and have been chiefly responsible for the slow development of new optical glasses. Even at present, unless the utmost care is exercised in procedures and techniques, striae will be found in most glasses.

After the final remelting, the glass was poured into a 3-in. diameter steel mold. As soon as it solidified, it was transferred to a heated, covered clay box and placed in an electric annealing furnace. The glasses were cooled through their annealing ranges at approximately $5 \mathrm{deg}$ C per hour.

The indices of refraction of the glasses were determined for the $C, D, F$, and $G^{\prime}$ lines by the Pulfrich method. ${ }^{4}$ The maximum error of a single determination should not exceed \pm 0.0001 .

For the glasses that were analyzed, it was found that except for a few glasses, the difference between the analyzed and batch compositions did not exceed 0.3 mole percent. The calculated compositions are given in the tables, as many of the glasses have not been analyzed. In general it is believed that the calculated compositions were more accurate than those determined by chemical analysis, particularly as duplicate glasses listed in the table indicated far less difference in composi-

\footnotetext{
${ }^{3}$ After most of the glasses had been made, it was found that striae-free glass could be made without remelting provided it was melted and stirred in a platinum crucible of the proper proportions. In a platinum crucible 3 in. in diameter by $3 \frac{1}{2}$ in. deep, 2-pound melts of striae-free glass have been made consistently.

${ }^{4}$ Determinations by I. Malitsky of this Bureau.
}

tion by their measured indices of refraction than by chemical analysis. For all but one set of duplicate glasses the measured indices of refraction $\left(n_{D}\right)$ agreed within 0.0001 .

The liquidus temperature of each glass was determined by a temperature gradient method [2]. The crystals formed in many of the glasses were very small, making it extremely difficult to determine the exact location in the specimen at which devitrification ceases. Complete identification of the crystal phases was not attempted. The appearance of a new crystalline phase at the liquidus was determined by petrographic examination. The crystallographic evidence indicates that the discontinuities found in the liquidus curves are accompanied by changes in the primary phase at the liquidus.

\section{Results and Discussions}

\section{Substitution of Beryllium Oxide for Barium Oxide}

The substitution of beryllium oxide for barium oxide produced glasses with lower indices of refraction and higher Abbe values than the base glass (table 1). No indices of refraction are given for melt 469, containing 12 mole percent of beryllium oxide, as this glass could not be cooled without devitrification.

A minimum point is ndicated on the liquiduscomposition curve, figure 1 , near the 6 -mole percent beryllium-oxide composition, and there is a definite change in slope of the index-of-refractioncomposition curves near this composition. Glasses containing 6-mole percent or less of beryllium oxide produced anisotropic crystals at the liquidus; the 8-mole percent glass, isotropic crystals; the 10-mole-percent glass, a mixture of isotropic and anisotropic crystals; and the 12-mole-percent glass, anisotropic crystals.

Abbe values ( $v$ ) have been plotted on this and succeeding figures. Discontinuities are usually found on the Abbe-value-composition curves at approximately the same compositions as on the other curves for the same series of glasses. Because of the large probable error in calculating Abbe values, discontinuities on the Abbe-valuecomposition curves were not considered significant.

\section{Substitution of Beryllium Oxide for Silica}

The substitution of beryllium oxide for silicaproduced glasses with higher indices of refraction 
TABle 1. Series 1. Substitution of beryllium oxide for barium oxide

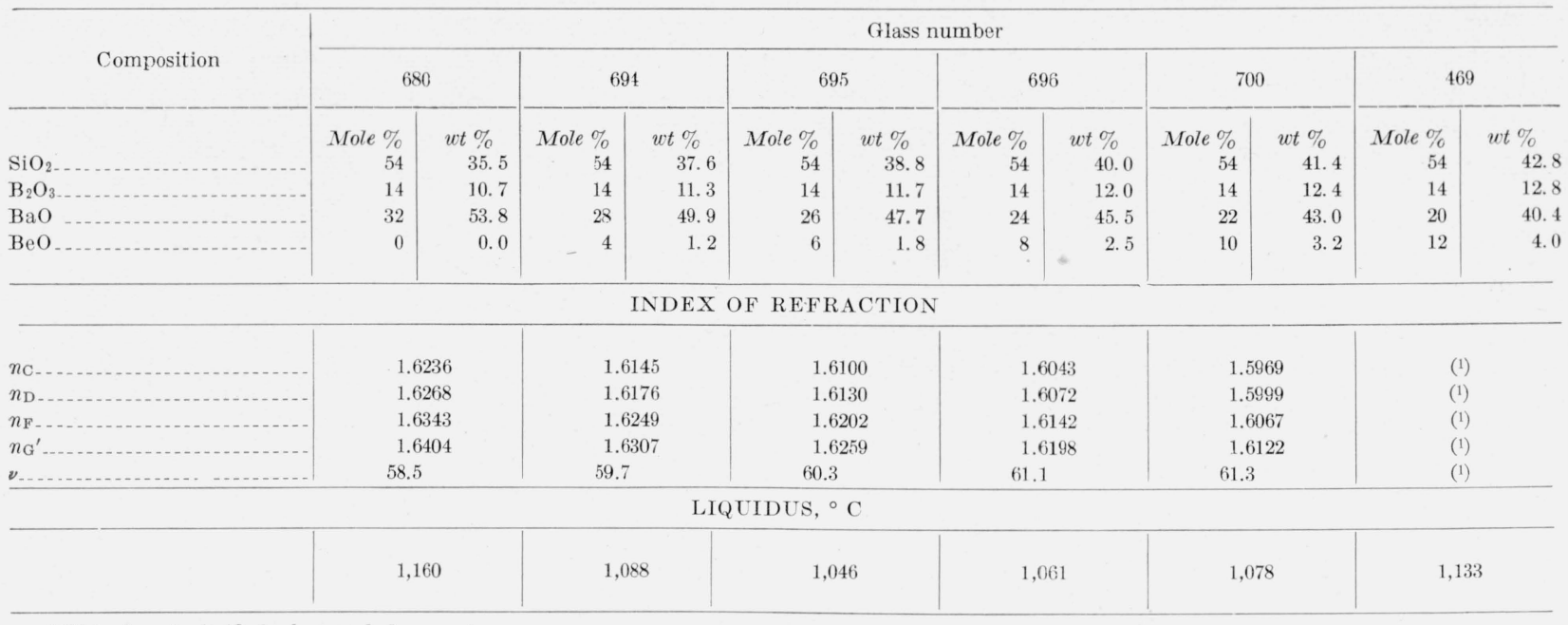

1 This glass devitrified when cooled.

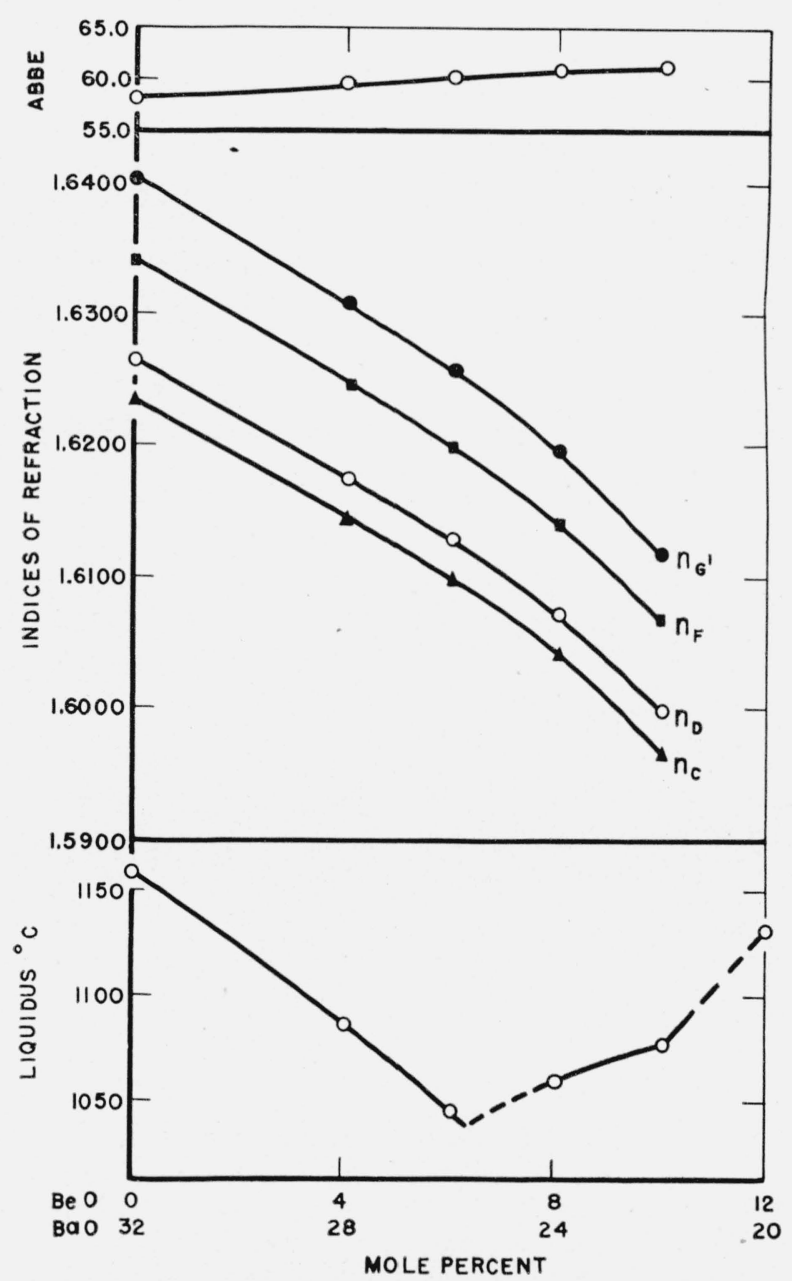

Figure 1. Effect of the substitution of beryllium oxide for barium oxide on the Abbe value, indices of refraction, and liquidus. and approximately the same Abbe values as the base glass (table 2). A change in slope of the index-of-refraction-composition curves was found near the glass composition containing 8-mole percent of beryllium oxide (fig. 2). This compo-

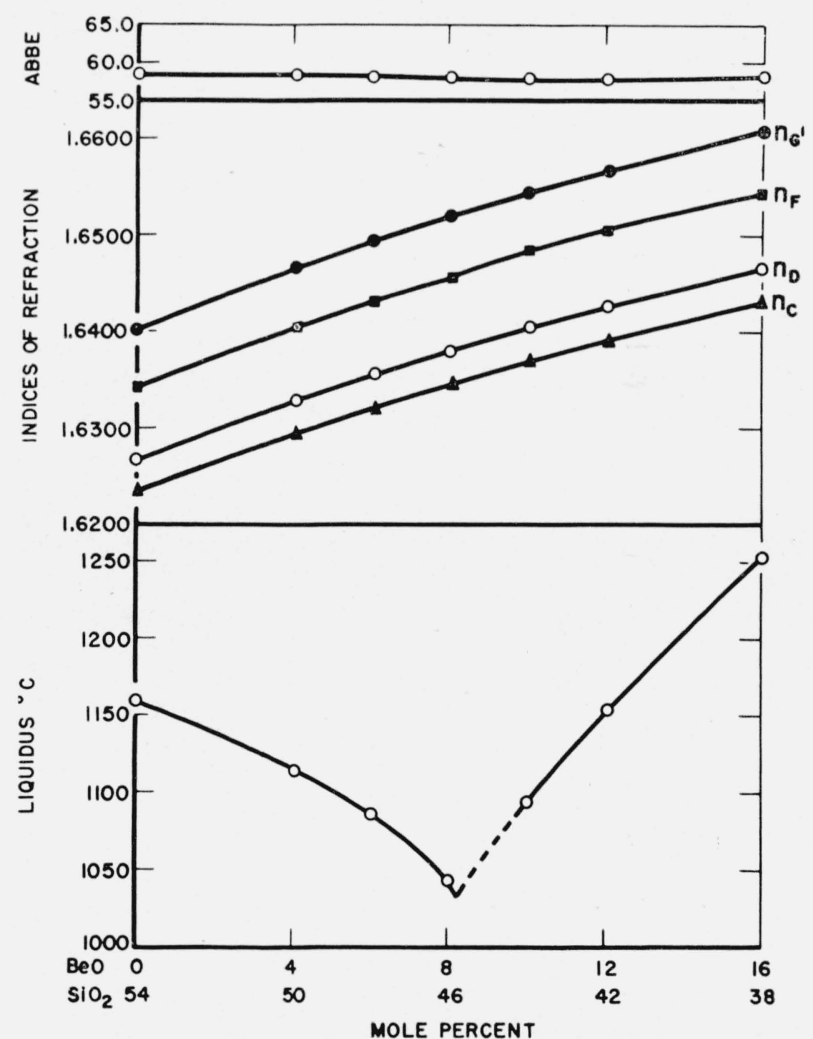

Figure 2. Effect of the substitution of beryllium oxide for silica on the Abbe value, indices of refraction, and liquidus. 
TABLE 2. Series 2. Substitution of beryllium oxide for silica

\begin{tabular}{|c|c|c|c|c|c|c|c|c|c|c|c|c|c|c|}
\hline \multirow{2}{*}{ Composition } & \multicolumn{14}{|c|}{ GLASS NUMBER } \\
\hline & \multicolumn{2}{|c|}{680} & \multicolumn{2}{|c|}{684} & \multicolumn{2}{|c|}{683} & \multicolumn{2}{|c|}{645 and $760{ }^{1}$} & \multicolumn{2}{|c|}{682} & \multicolumn{2}{|c|}{681 and 7041} & \multicolumn{2}{|c|}{705} \\
\hline $\mathrm{B}_{2} \mathrm{O}_{3}$ & 14 & 10.7 & 14 & 10.9 & 14 & 10.9 & 14 & 11.0 & 14 & 11.1 & 14 & 11. 2 & 14 & 11.4 \\
\hline $\mathrm{BaO}_{\text {. }}$ & 32 & 53.8 & 32 & 54.6 & 32 & 55.1 & 32 & 55.5 & 32 & 55.9 & 32 & 56.4 & 32 & 57.3 \\
\hline
\end{tabular}

INDEX OF REFRACTION

\begin{tabular}{|c|c|c|c|c|c|c|c|c|c|}
\hline$n_{C} \ldots \ldots$ & 1. 6236 & 1. 6297 & 1. 6325 & 1. 6349 & 1. 6349 & 1. 6375 & 1. 6395 & 1. 6395 & 1. 6437 \\
\hline$n_{F-\ldots}$ & 1. 6343 & 1. 6405 & 1. 6434 & 1. 6458 & 1. 6459 & 1.6486 & 1. 6506 & 1.6506 & 1. 6548 \\
\hline$n_{G^{\prime} \ldots}$ & 1. 6404 & 1. 6467 & 1. 6496 & 1. 6518 & 1. 6521 & 1. 6548 & 1. 6569 & 1. 6569 & 1. 6611 \\
\hline$\nu_{\ldots} \ldots$ & 58.5 & 58.6 & 58.4 & 58.3 & 58.3 & 58.1 & 58.0 & 57.9 & 58.3 \\
\hline & 1. 160 & 1,115 & 1,088 & 1,049 & 1,040 & 1,096 & 1,156 & 1,163 & 1,258 \\
\hline
\end{tabular}

${ }^{1}$ Duplicate batch compositions.

sition is approximately at the minimum of the liquidus-composition curve. All glasses in this series produced anisotropic crystals at the liquidus temperature. Crystals from glasses containing 8mole percent or less of beryllium oxide has a maximum index of refraction of 1.605 ; for crystals from the other glasses this value was 1.655 .
For optical glasses of this type, 6 to 8 mole percent of beryllium oxide appears to be the optimum concentration, as this amount produces glasses with the lowest liquidus temperature. If the concentration of beryllium is further increased, the liquidus temperature increases rapidly, the glasses are more difficult to fine, and the tendency

TaBle 3. Series 3. Substitution of calcium oxide for barium oxide

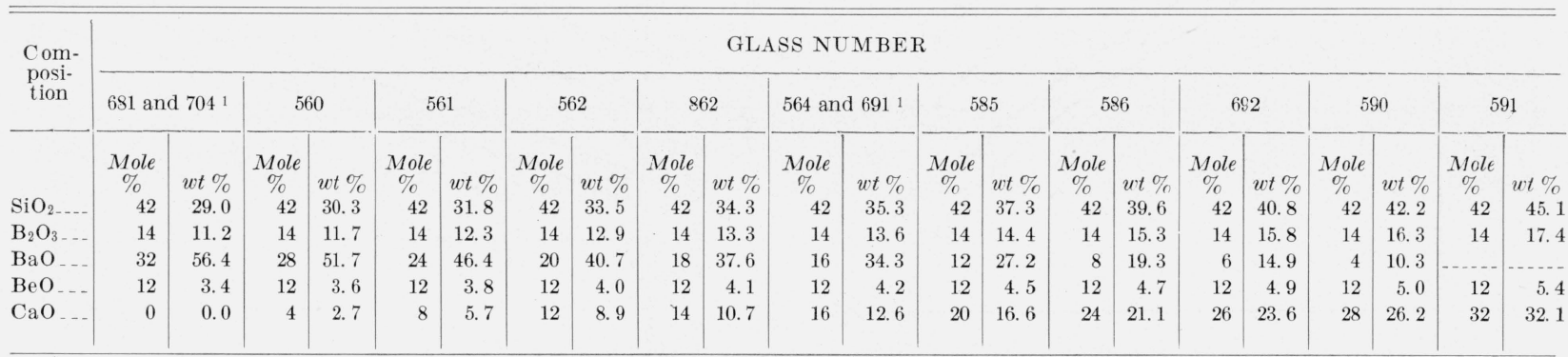

\section{INDEX OF REFRACTION}

\begin{tabular}{|c|c|c|c|c|c|c|c|c|c|c|c|c|c|}
\hline & 681 & 704 & 560 & 561 & 562 & 862 & 564 & 691 & 585 & 586 & 692 & 590 & 591 \\
\hline$n_{C \ldots}$ & 1. 6395 & 1. 6395 & 1. 6355 & 1. 6316 & 1. 6256 & 1. 6230 & 1. 6207 & 1. 6207 & 1. 6158 & 1. 6101 & 1. 6076 & 1. 6053 & $\left({ }^{2}\right)$ \\
\hline$n_{P_{-}}$ & 1. 6506 & 1. 6506 & 1. 6464 & 1.6424 & 1. 6362 & 1. 6335 & 1. 6311 & 1. 6311 & 1. 6261 & 1. 6202 & 1. 6177 & 1. 6154 & () \\
\hline$n_{G^{\prime}}$ & 1. 6569 & 1. 6569 & 1. 6526 & 1.6485 & 1. 6422 & 1. 6395 & 1. 6371 & 1. 6371 & 1. 6320 & 1. 6261 & 1. 6234 & 1. 6210 & () \\
\hline$\nu \ldots$ & 58.0 & 57.9 & 58.6 & 59.0 & 59.3 & 59.5 & 59.6 & 59.6 & 59.8 & 60.6 & 60.4 & 60.3 & () \\
\hline \multicolumn{14}{|c|}{ LIQUIDUS, ${ }^{\circ} \mathrm{C}$} \\
\hline & 1,156 & 1,163 & 1,153 & 1,150 & 1,138 & 1,131 & 1,114 & 1,111 & 1,080 & 1,050 & 1,013 & 1,052 & 1,150 \\
\hline
\end{tabular}


of the glasses to devitrify increases. Therefore, the glass containing 8 mole percent of beryllium oxide in this series was used as the base composition for other series of melts.

\section{Substitution of Calcium Oxide for Barium Oxide}

The substitution of calcium oxide for barium oxide produced glasses with lower indices of refraction and higher Abbe values than the base glass (table 3). A minimum liquidus temperature was found at approximately 26 mole percent of calcium oxide.

With the exception of melts $681,704,691$, and 692 , the glasses in this series were not remelted. As the amount of calcium oxide in the glass was increased, the quality of the glasses improved with respect to their striae content. Glasses containing 16 mole percent or more of calcium oxide were obtained free from striae. The measured indices of refraction of glasses $5 € 0,561$, and 562 may not

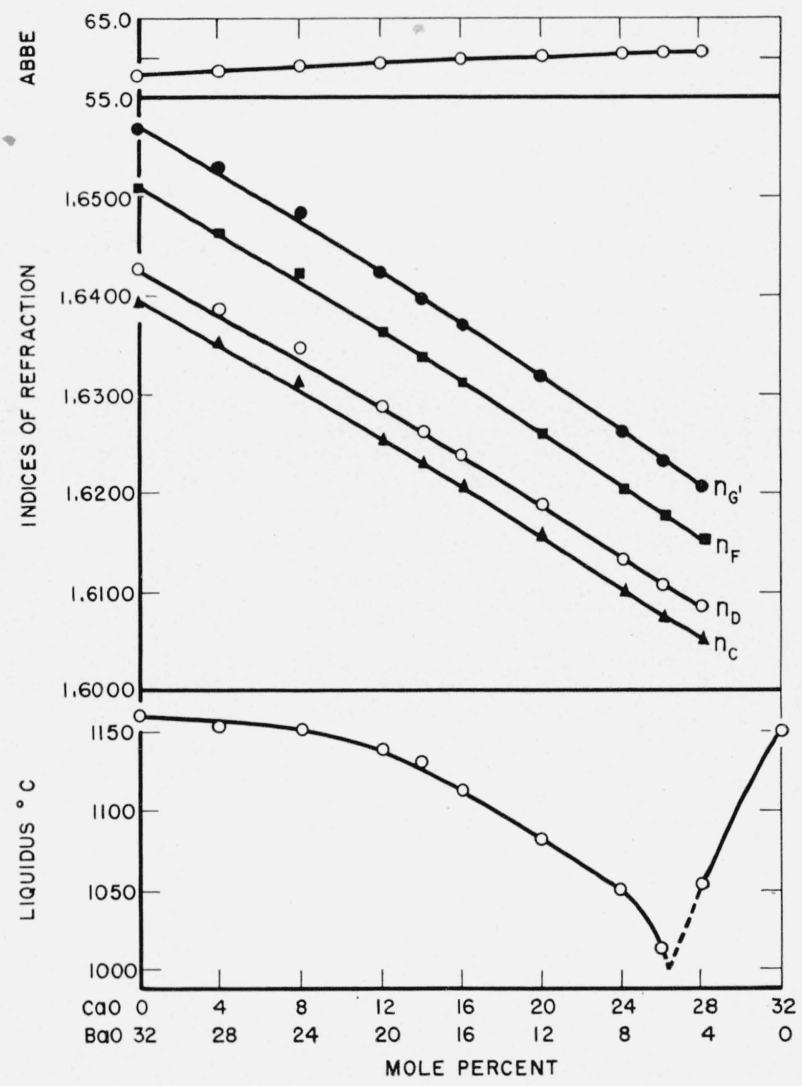

Figure 3. Effect of the substitution of calcium oxide for barium oxide on the Abbe value, indices of refraction, and liquidus. be reliable because of the presence of striae. For this reason, they were not considered in drawing the index-of-refraction-composition curves of figure 3.

No indices of refraction are given for melt 591 as this composition could not be cooled without devitrification. Consequently, the calcium oxide content of glasses of this type should not greatly exceed that of the glass having the minimum liquidus.

\section{Substitution of Lanthanum Oxide for Barium Oxide}

The substitution of lanthanum oxide for barium oxide produced glasses with the highest indices of refraction of any of the series of melts discussed in this paper (table 4). The increase in index of refraction averages 0.0056 per mole percent substituted. Discontinuities were found in the liquidus-composition and in the index-of-refractioncomposition curves near the compositions containing 1 and 6 mole percent of lanthanum oxide (fig. 4). A straight line could fit the index of refraction data almost as well as the three lines drawn in figure 4. However, examination reveals systematic deviations from the straight line was compared with the random deviations, because of experimental error, which results when the index line is drawn in segments corresponding to the breaks in the liquidus curve. The liquidus temperature of the glasses increased very rapidly as the concentration of lanthanum oxide was increased above 6 mole percent with a corresponding increase in the difficulty of melting and fining the glasses. Melt 650 containing 12 mole percent of lanthanum oxide was very difficult to melt and contained striae, making a determination of the index of refraction for the $G^{\prime}$ line impossible. Because of these difficulties, the preparation of glasses containing larger amounts of lanthanum oxide was not attempted.

\section{Substitution of Thoria for Barium Oxide}

The substitution of thoria for barium-oxide produced glasses with higher indices of refraction and lower Abbe values than the base glass (table 5). The average increase in index of refraction was 0.0028 per mole percent of thoria substituted for barium oxide. As the thoria content of the glasses was increased up to 4 mole percent, the 


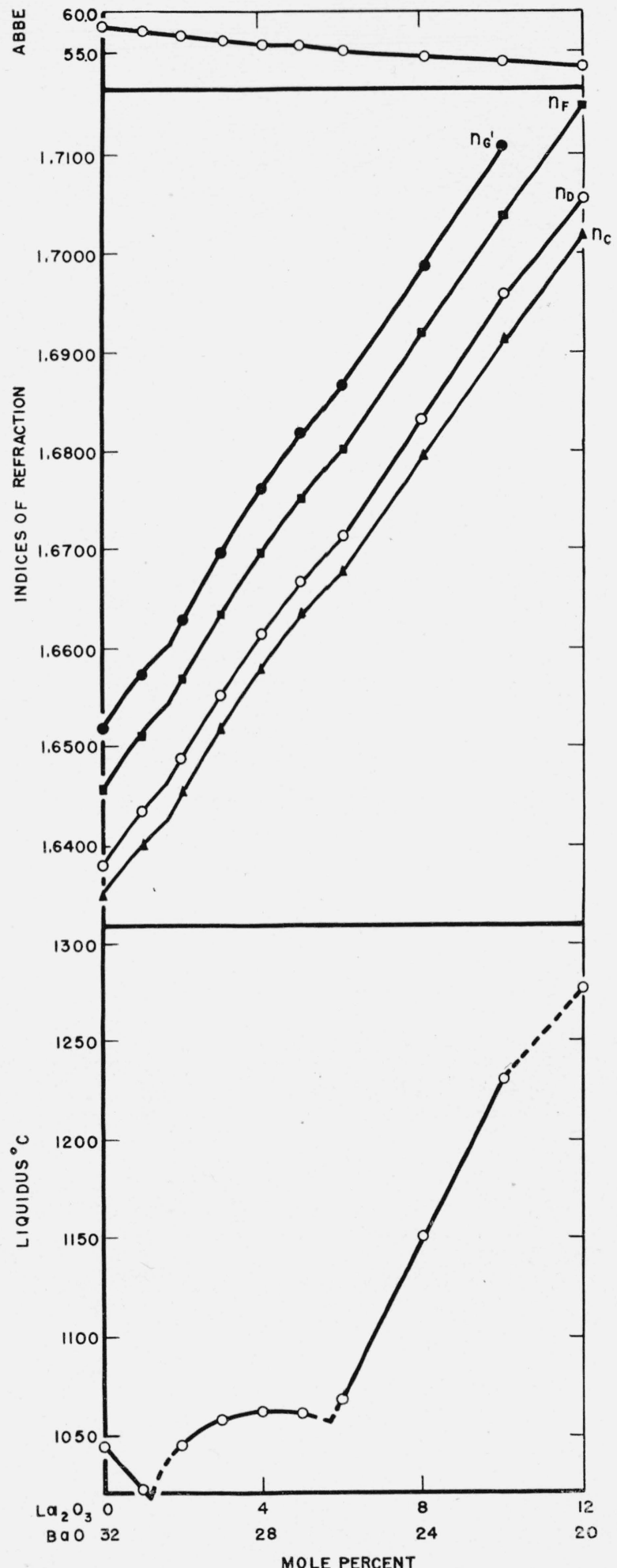

FIGURE 4. Effect of the substitution of lanthanum oxide for barium oxide on the Abbe value, indices of refraction, and liquidus.

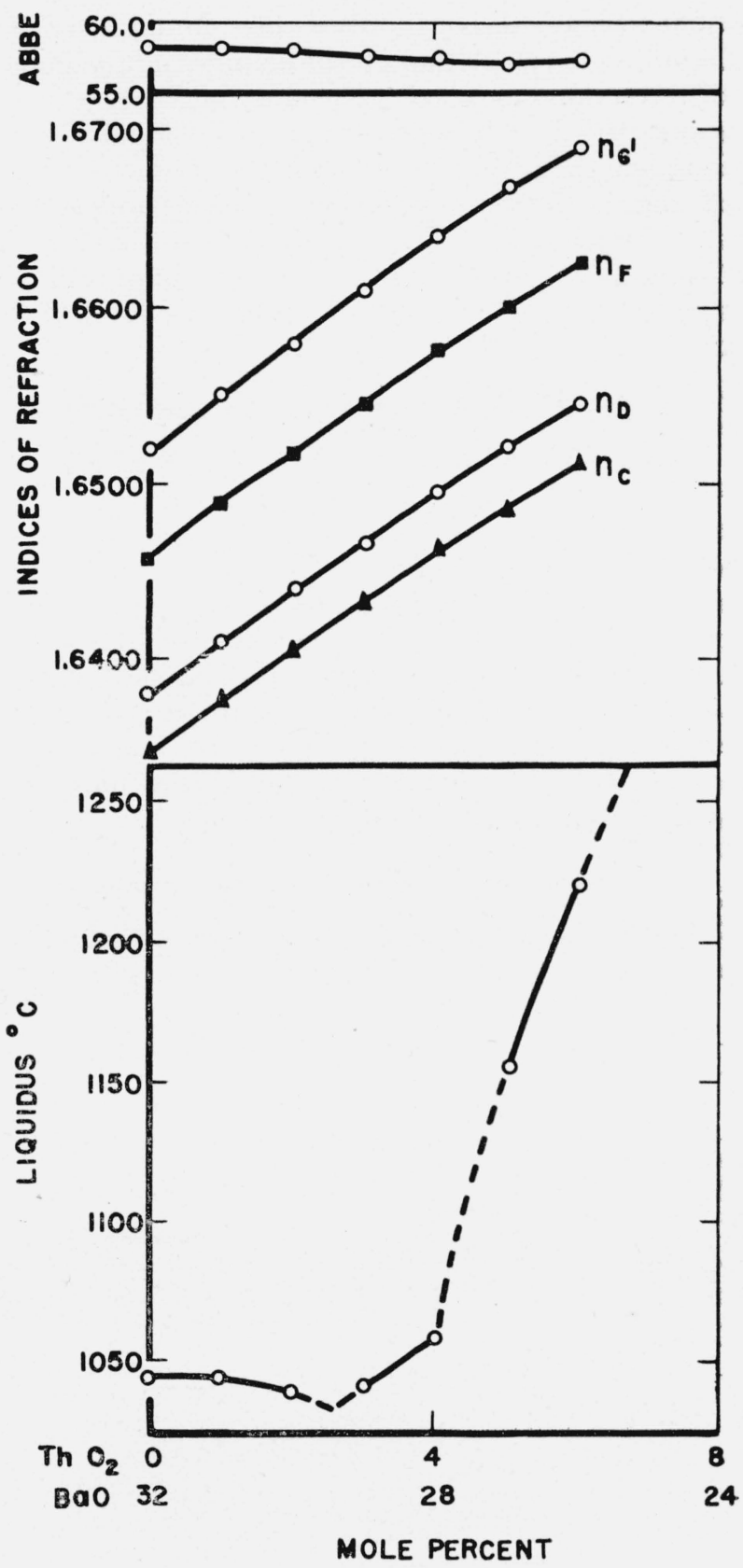

FIgURE 5. Effect of the substitution of thorium oxide for barium oxide on the Abbe value, indices of refraction, and liquidus.

liquidus changed very little, but further increases produced a large increase in liquidus temperature. Two discontinuities were found in the liquiduscomposition curve (fig. 5) in the region containing3 and 4 mole percent of thoria. When the indices of refraction are plotted against compositions, very slight changes in slope appear at the same composi- 
tions where discontinuities are found on the liquidus curve. Although the changes on the index of refraction curve are sufficiently slight to permit a smooth curve to represent the data equally well, it is felt that by analogy with the previous series of glasses the representation of discontinuities in slope is justified. The series was discontinued with the melt containing 8 mole percent of thoria, as this melt could not be cooled without devitrification.

\section{Substitution of Lithia for Barium Oxide}

Lithia up to 16 mole percent was substituted for barium oxide in composition number 645 . The indices of refraction and liquidus temperature of the glasses decreased, and the Abbe values increased as the lithia content of the glasses was increased (table 6 and fig. 6). The fluidity of the melts increased with increase in their lithia content. All the glasses produced the same type of crystals at the liquidus temperature, and no discontinuities were found in the liquidus-or index-ofrefraction-composition curves of figure 6 .

\section{Substitution of Boron Oxide for Silica}

The liquidus temperature of most of the melts previously discussed was $1,040^{\circ} \mathrm{C}$ or higher. It

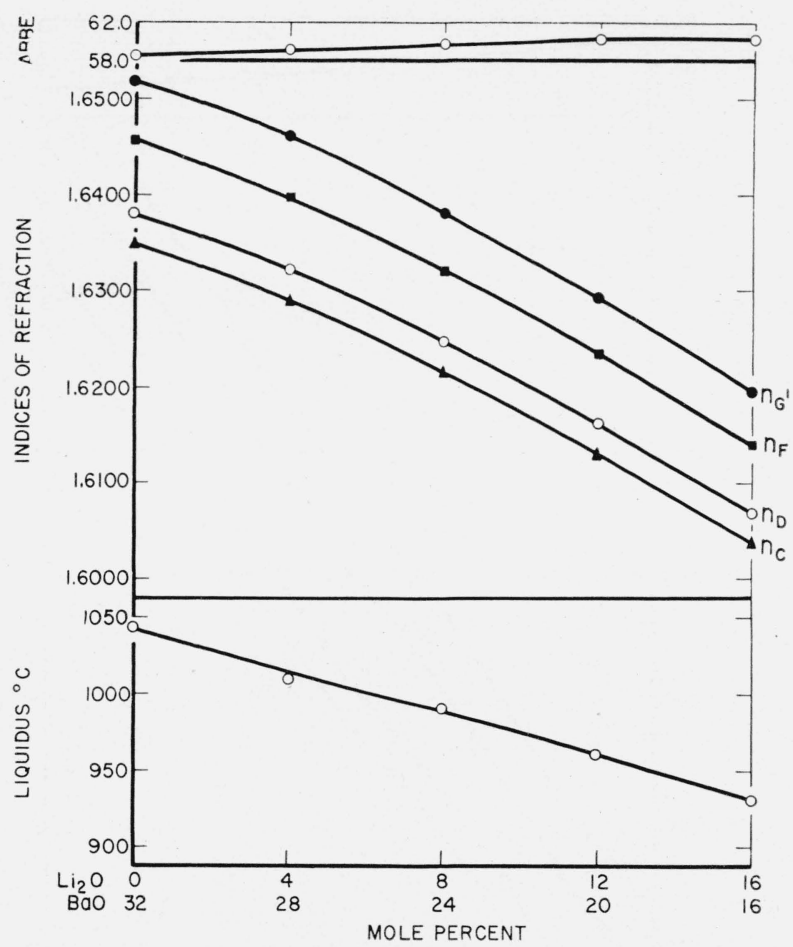

Figure 6. Fffect of the substitution of lithium oxide for barium oxide on the Abbe value, indices of refraction, and liquidus.

Table 6. Series 6. Substitution of lithium oxide for barium oxide

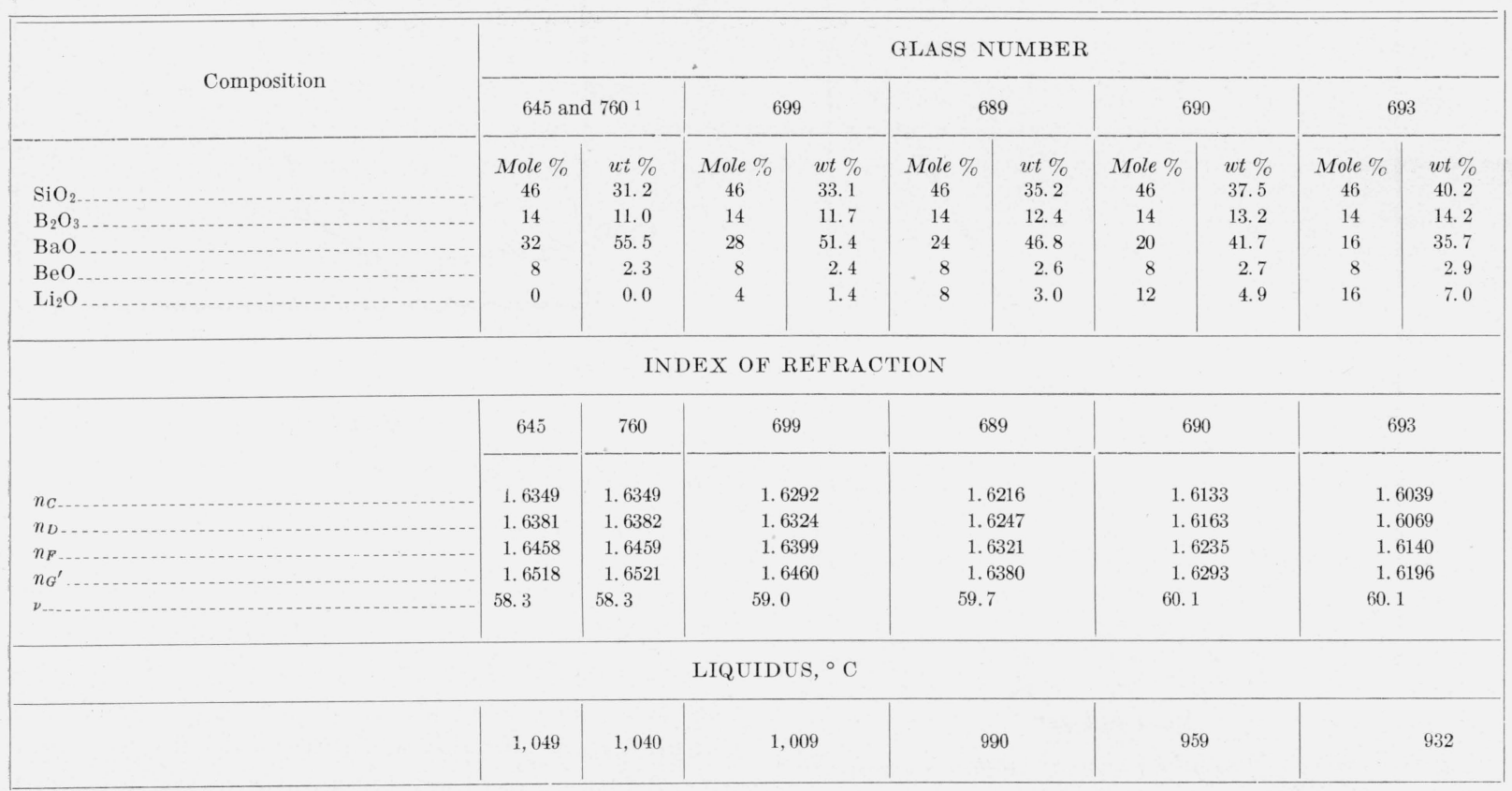

1 Duplicate batch compositions. 
TaBle 7. Series \%. Substitution of boron oxide for silica

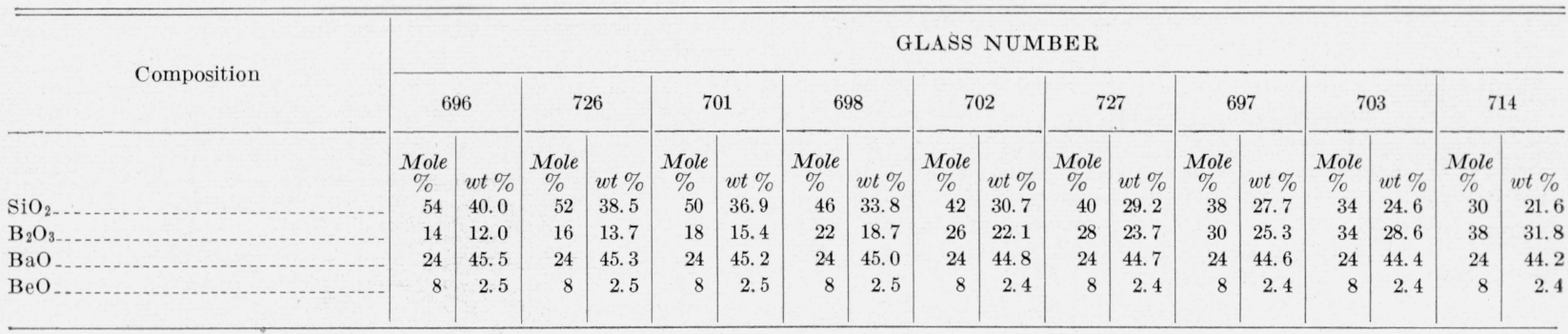

INDEX OF REFRACTION

\begin{tabular}{|c|c|c|c|c|c|c|c|c|c|}
\hline$n_{C--}$ & 1. 6043 & 1. 6053 & 1. 6059 & 1. 6070 & 1. 6065 & 1. 6067 & 1. 6064 & 1. 6052 & 1. 6039 \\
\hline$n_{D} \ldots \ldots$ & 1. 6072 & 1. 6083 & 1. 6089 & 1. 6100 & 1. 6095 & 1. 6096 & 1. 6093 & 1. 6082 & 1. 6068 \\
\hline$n_{F} \ldots \ldots \ldots$ & 1. 6142 & 1. 6153 & 1. 6159 & 1. 6170 & 1. 6164 & 1.6165 & 1. 6163 & 1. 6150 & 1. 6137 \\
\hline$n_{G^{\prime}}^{\prime}$ & 1. 6198 & 1. 6209 & 1. 6215 & 1. 6225 & 1. 6219 & 1.6220 & 1. 6217 & 1. 6204 & 1. 6191 \\
\hline$\nu_{-}$ & 61.1 & 61.4 & 61.3 & 61.4 & 62.0 & 62.0 & 62.0 & 62.4 & 62.2 \\
\hline \multicolumn{10}{|c|}{ LIQUIDUS, ${ }^{\circ} \mathrm{C}$} \\
\hline & 1,061 & 1,030 & 1,002 & 962 & 927 & 943 & 940 & 936 & 903 \\
\hline
\end{tabular}

was believed that glasses with lower liquidus and higher indices of refraction and Abbe values could be produced by substituting boron oxide for silica, and five series of glasses were prepared in which this substitution was made.

Boron oxide was substituted for silica in glass no. 696 (table 1). The compositions and data for the glasses are given in table 7 and plotted in figure 7. This substitution produced glasses with lower liquidus temperatures and higher Abbe values than the base glass. It had an anomalous

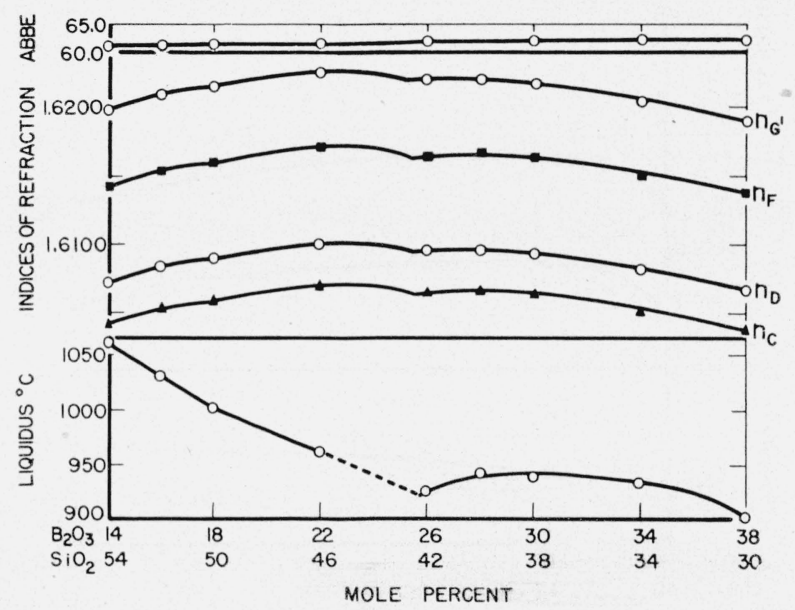

Figure 7. Effect of the substitution of boron oxide for silica in glass 696 on the Abbe value, indices of refraction, and liquidus. effect on the indices of refraction. The index of refraction $\left(n_{D}\right)$ increased from 1.6072 to 1.6100 , and then decreased to 1.6068 as the boron oxide content of the melts was increased from 14 to 38 mole percent. The maximum index of refraction was found near 22 mole percent of boron oxide.

Two discontinuities were found in the liquiduscomposition and index-of-refraction-composition curves at the 18 and near the 26 mole percent of boron-oxide composition. Glasses containing 26 mole percent or less of boron oxide produced isotropic crystals at the liquidus, whereas the glasses containing 28 mole percent or more produced anisotropic crystals. As the boron oxide content of the glasses was increased the liquidus temperature decreased from $1,061^{\circ}$ to $903^{\circ} \mathrm{C}$.

Boron oxide was substituted for silica in glass no. 645 (table 2). The substitution of boron oxide for silica produced the same anomalous effect on the index of refraction as in the preceding series. Maxima were found in the index-ofrefraction-composition curves at 22 and 26 mole percent of boron oxide (table 8 and fig. 8). Discontinuities were found in the index-of-refractioncomposition and liquidus-composition curves near 18 and 24 mole percent of boron oxide. The liquidus decreased from $1,054^{\circ}$ to $960^{\circ} \mathrm{C}$ and then increased slightly to $970^{\circ} \mathrm{C}$ as the boron oxide content of the glasses was increased. The Abbe values of the glasses increased as their boron oxide content was increased. 
Table 8. Series 8. Substitution of boron oxide for sitica

\begin{tabular}{|c|c|c|c|c|c|c|c|c|c|c|c|c|c|c|c|c|}
\hline \multirow{2}{*}{ Composition } & \multicolumn{14}{|c|}{ GLASS NUMBER } & \multicolumn{2}{|l|}{. } \\
\hline & \multicolumn{2}{|c|}{645 and $760^{1}$} & \multicolumn{2}{|c|}{730} & \multicolumn{2}{|c|}{688} & \multicolumn{2}{|c|}{687} & \multicolumn{2}{|c|}{731} & \multicolumn{2}{|c|}{686} & \multicolumn{2}{|c|}{685 and $706^{1}$} & \multicolumn{2}{|c|}{715} \\
\hline $\mathrm{SiO}_{2}$ & $\begin{array}{r}\text { Mole } \% \\
46\end{array}$ & $\begin{array}{l}w t \% \\
31.2\end{array}$ & $\begin{array}{c}\text { Mole \% } \\
44\end{array}$ & $\begin{array}{r}w t \% \\
29.8\end{array}$ & $\begin{array}{c}\text { Mole } \% \\
42\end{array}$ & $\begin{array}{r}w t \% \\
28.4\end{array}$ & $\begin{array}{c}\text { Mole \% } \\
38\end{array}$ & $\begin{array}{r}w t \% \\
25.6\end{array}$ & $\begin{array}{c}\text { Mole \% } \\
36\end{array}$ & $\begin{array}{r}w t \% \\
24.2\end{array}$ & $\begin{array}{c}\text { Mole } \% \\
34\end{array}$ & $\begin{array}{r}w t \% \\
22.8\end{array}$ & $\begin{array}{r}\text { Mole \% } \\
30\end{array}$ & $\begin{array}{l}w t \% \\
20.0\end{array}$ & $\begin{array}{c}\text { Mole } \% \\
26\end{array}$ & $\begin{array}{l}w t \% \\
17.3\end{array}$ \\
\hline $\mathrm{B}_{2} \mathrm{O}_{3} \ldots$ & 14 & 11.0 & 16 & 12.6 & 18 & 14.1 & 22 & 17.2 & 24 & 18.7 & 26 & 20.2 & 30 & 23.2 & 34 & 26.2 \\
\hline $\mathrm{BaO} \ldots$ & 32 & 55.5 & 32 & 55.3 & 32 & 55.2 & 32 & 55.0 & 32 & 54.9 & 32 & 54.8 & 32 & 54.6 & 32 & 54.3 \\
\hline $\mathrm{BeO}$ & 8 & 2.3 & 8 & 2.3 & 8 & 2.3 & 8 & 2.2 & 8 & 2.2 & 8 & 2.2 & 8 & 2.2 & 8 & 2. 2 \\
\hline
\end{tabular}

INDEX OF REFRACTION

\begin{tabular}{|c|c|c|c|c|c|c|c|c|c|c|}
\hline & 645 & 760 & 730 & 688 & 687 & 731 & 686 & 685 & 706 & 715 \\
\hline$n_{C \ldots} \ldots$ & 1. 6349 & 1. 6349 & 1. 6353 & 1. 6354 & 1. 6365 & 1. 6357 & 1. 6363 & 1. 6355 & 1. 6353 & 1. 6337 \\
\hline$n_{D} \ldots \ldots$ & 1. 6381 & 1. 6382 & 1. 6385 & 1. 6386 & 1. 6397 & 1. 6388 & 1. 6395 & 1. 6386 & 1. 6385 & 1. 6368 \\
\hline$n_{F} \ldots$ & 1. 6458 & 1. 6459 & 1. 6461 & 1. 6463 & 1. 6473 & 1. 6464 & 1. 6470 & 1. 6461 & 1. 6460 & 1. 6443 \\
\hline$n_{G^{\prime}} \ldots \ldots$ & 1. 6518 & 1. 6521 & 1. 6524 & 1. 6525 & 1. 6535 & 1. 6525 & 1. 6531 & 1. 6522 & 1. 6521 & 1. 6502 \\
\hline$\nu \ldots \ldots$ & 58.3 & 58.3 & 58.6 & 58.7 & 59.2 & 59.6 & 59.7 & 59.9 & 59.8 & 60.4 \\
\hline \multicolumn{11}{|c|}{ LIQUIDUS, ${ }^{\circ} \mathrm{C}$} \\
\hline & 1,049 & 1,040 & 1,028 & 1,005 & 985 & 972 & 962 & 968 & 968 & 970 \\
\hline
\end{tabular}

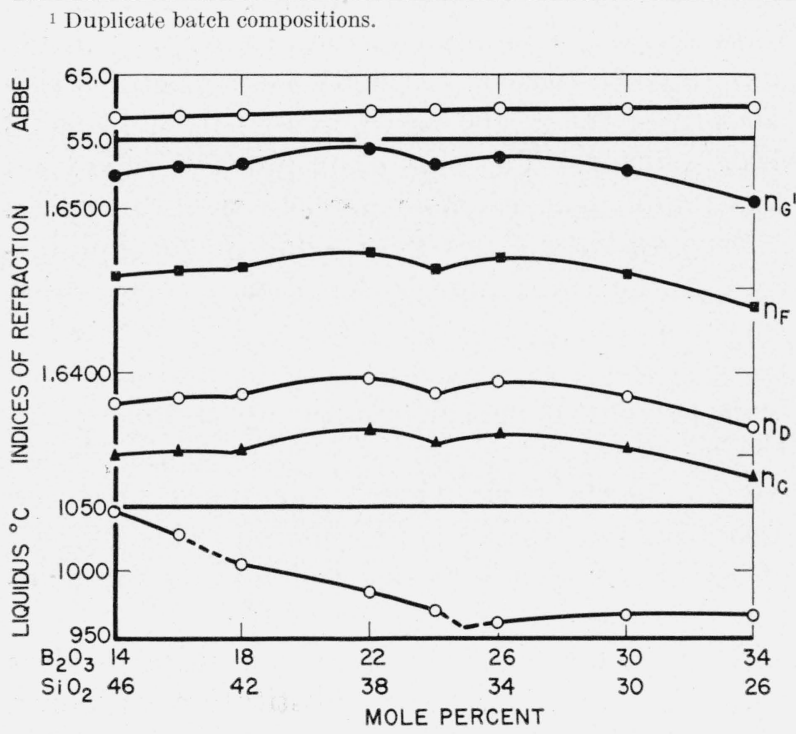

Figure 8. Effect of the substitution of boron oxide for silica in glass 645 on the Abbe value, indices of refraction, and liquidus.

Boron oxide was substituted for silica in glass No. 647 (table 4) containing 6 mole percent of lanthanum oxide. The indices of refraction of the glasses increased and then decreased (table 9 and fig. 9) as the boron oxide content of the glasses increased from 14 to 34 mole percent. The glass containing 22 mole percent of boron oxide had the highest index of refraction of any glass in this series. The liquidus of the glasses decreased to a

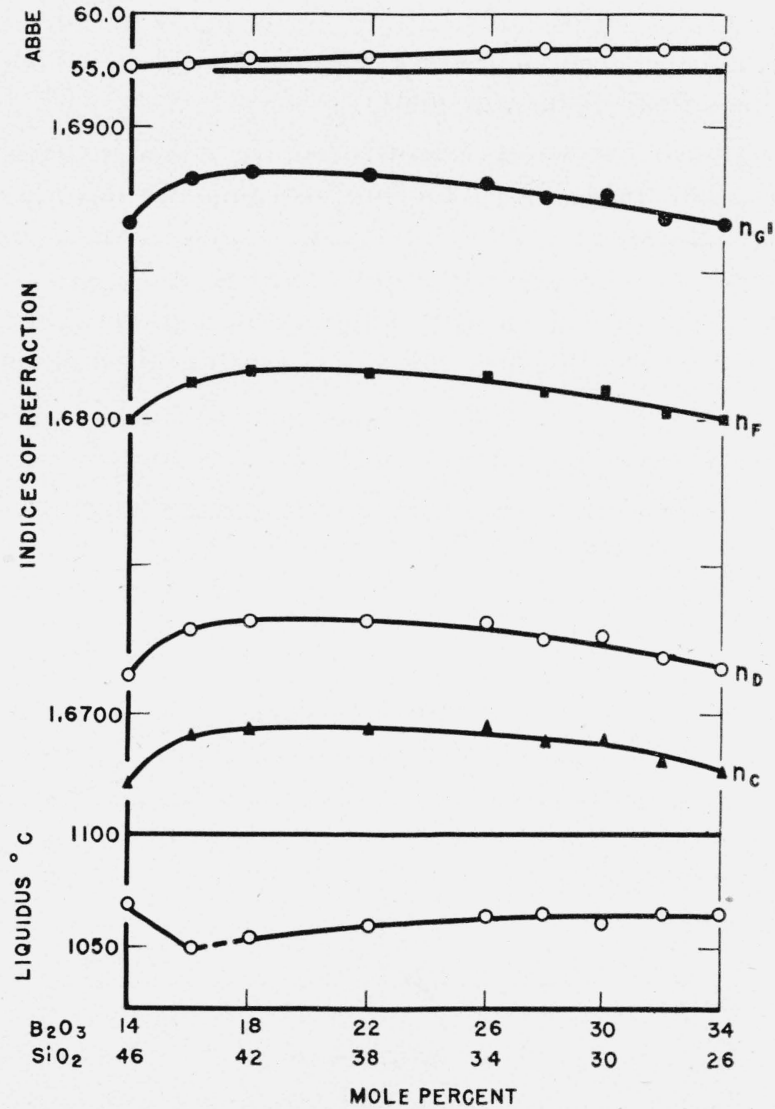

Figure 9. Effect of the substitution of boron oxide for silica in glass 647 on the Abbe value, indices of refraction, and liquidus. 
Table 9. Series 9. Substitution of boron oxide for silica

\begin{tabular}{|c|c|c|c|c|c|c|c|c|c|c|c|c|c|c|c|c|c|c|}
\hline Composition & \multicolumn{2}{|c|}{647} & \multicolumn{2}{|c|}{736} & \multicolumn{2}{|c|}{652} & \multicolumn{2}{|c|}{ 653. 711 , and $723{ }^{1}$} & \multicolumn{2}{|c|}{654} & \multicolumn{2}{|c|}{737} & \multicolumn{2}{|c|}{911} & \multicolumn{2}{|c|}{773} & \multicolumn{2}{|c|}{713} \\
\hline $\mathrm{B}_{2} \mathrm{O}_{3 \ldots} \ldots$ & 14 & 9.9 & 16 & 11.2 & 18 & 12.6 & 22 & 15.4 & 26 & 18.1 & 28 & 19.5 & 30 & 20.8 & 32 & 22.2 & 34 & 23.5 \\
\hline $\mathrm{BaO}_{\ldots}$ & 26 & 40.3 & 26 & 40.3 & 26 & 40.2 & 26 & 40.0 & 26 & 39.9 & 26 & 39.8 & 26 & 39.7 & 26 & 39.6 & 26 & 39.6 \\
\hline
\end{tabular}

INDEX OF REFRACTION

\begin{tabular}{|c|c|c|c|c|c|c|c|c|c|c|c|}
\hline & 647 & 736 & 652 & 653 & 711 & 723 & 654 & 737 & 911 & 773 & 713 \\
\hline$n_{C \ldots}$ & 1. 6677 & 1. 6693 & 1. 6695 & 1. 6697 & 1. 6695 & 1. 6694 & 1. 6695 & 1.6680 & 1. 6691 & 1. 6684 & 1. 6681 \\
\hline$n_{D \ldots}$ & 1.6713 & 1. 6729 & 1.6731 & 1. 6733 & 1. 6731 & 1. 6729 & 1.6731 & 1. 6725 & 1. 6726 & 1. 6719 & 1. 6716 \\
\hline$n c^{\prime} \ldots$ & 1. 6867 & 1. 6884 & 1. 6884 & 1. 6886 & 1. 6884 & 1. 6882 & 1. 6881 & 1. 6876 & 1. 6878 & 1. 6869 & 1. 6866 \\
\hline$\nu \ldots$ & 55.2 & 55.5 & 55.9 & 55.9 & 55.9 & 55.9 & 56.5 & 56.5 & 56.6 & 56.8 & 56.8 \\
\hline
\end{tabular}

LIQUIDUS, ${ }^{\circ} \mathrm{C}$

\begin{tabular}{r|r|r|r|r|r|r|r|r|r|r|r|r|r|}
\hline & 1,069 & 1,051 & 1,055 & 1,058 & 1,059 & 1,066 & 1,064 & 1,064 & 1,060 & 1,066 \\
\hline
\end{tabular}

${ }_{1}$ Duplicate batch compositions.

minimum of $1,051^{\circ} \mathrm{C}$ for the glass containing 16 mole percent of boron oxide; then it increased to $1,165^{\circ} \mathrm{C}$ at approximately 26 mole percent and remained fairly constant as the boron oxide content was increased. In this respect, this series of glasses differs from all the other series in which boron oxide was substituted for silica. All of the glasses in this series produced anisotropic crystals at the liquidus; those from the glasses containing 14 to 16 mole percent of boron oxide were needlelike. The crystals from the other glasses were very small and had rounded edges.

TABLE 10. Twelve mole percent lanthanum oxide glasses

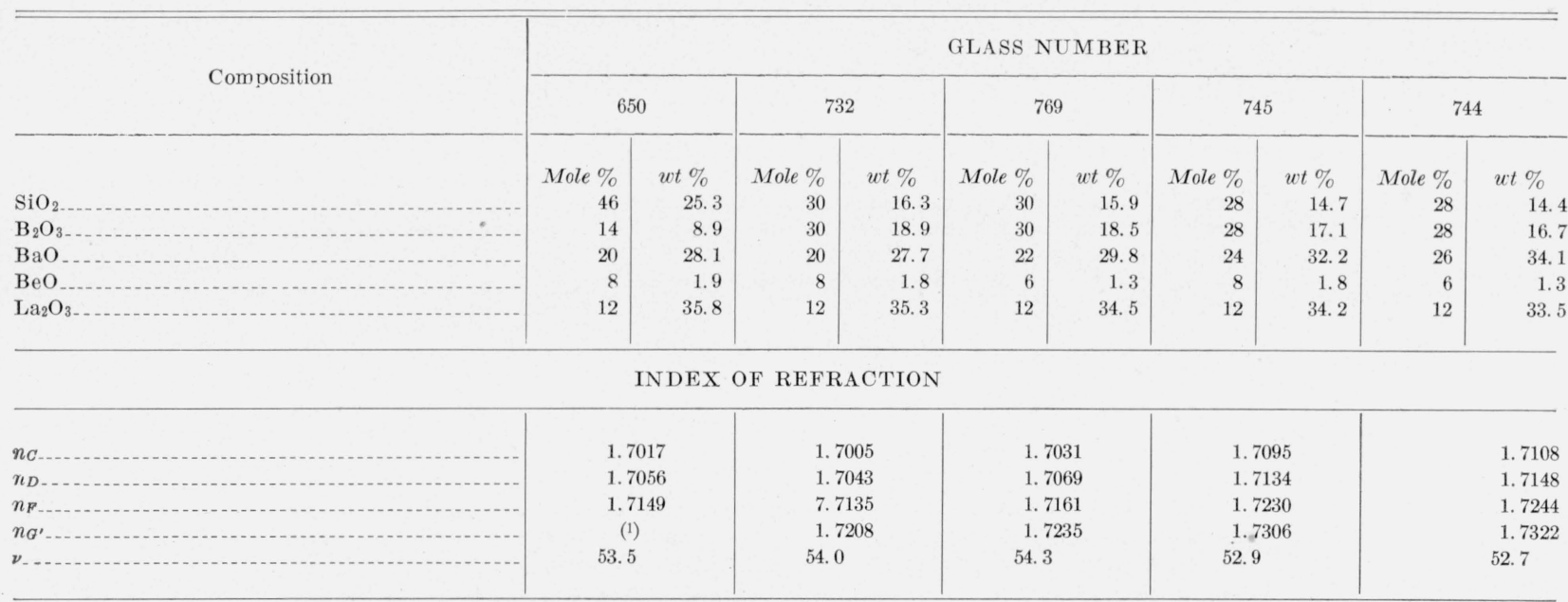

LIQUIDUS, ${ }^{\circ} \mathrm{C}$ 
Glass no. 650 containing 12 mole percent of lanthanum oxide had a high index of refraction $\left(n_{D}=1.7056\right)$, an Abbe value of 53.5 and a liquidus of $1,276^{\circ} \mathrm{C}$. Boron oxide was substituted for 16 mole percent of silica to determine whether this substitution would produce a glass with similar optical properties and a substantially lower liquidus temperature. The resulting glass, melt 732 of table 10, had an index of refraction, $n_{D}$, of 1.7043, Abbe value of 54.0 and a liquidus of $1,164^{\circ} \mathrm{C}$, which is more than $100^{\circ} \mathrm{C}$ below the liquidus temperature of melt 650 . The substitution of barium oxide for beryllium oxide or for silica and boron oxide in composition 732 produced glasses with approximately the same liquidus temperatures but with higher indices of refraction and, in the case of two of the glasses, lower Abbe values (see melts 769, 745, and 744 of table 10). Attempts to cool 1,000-g melts of compositions 732 and 745 in the form of a block approximately 1 nch thick resulted in considerable devitrification. Work is in progress to alter these glasses so that they can be cooled without devitrification.

Boron oxide was substituted for silica in glass number 671 containing 4 mole percent of thoria. The index of refraction increased and then decreased (table 11 and fig. 10). The maximum index of refraction appeared to be at a composition

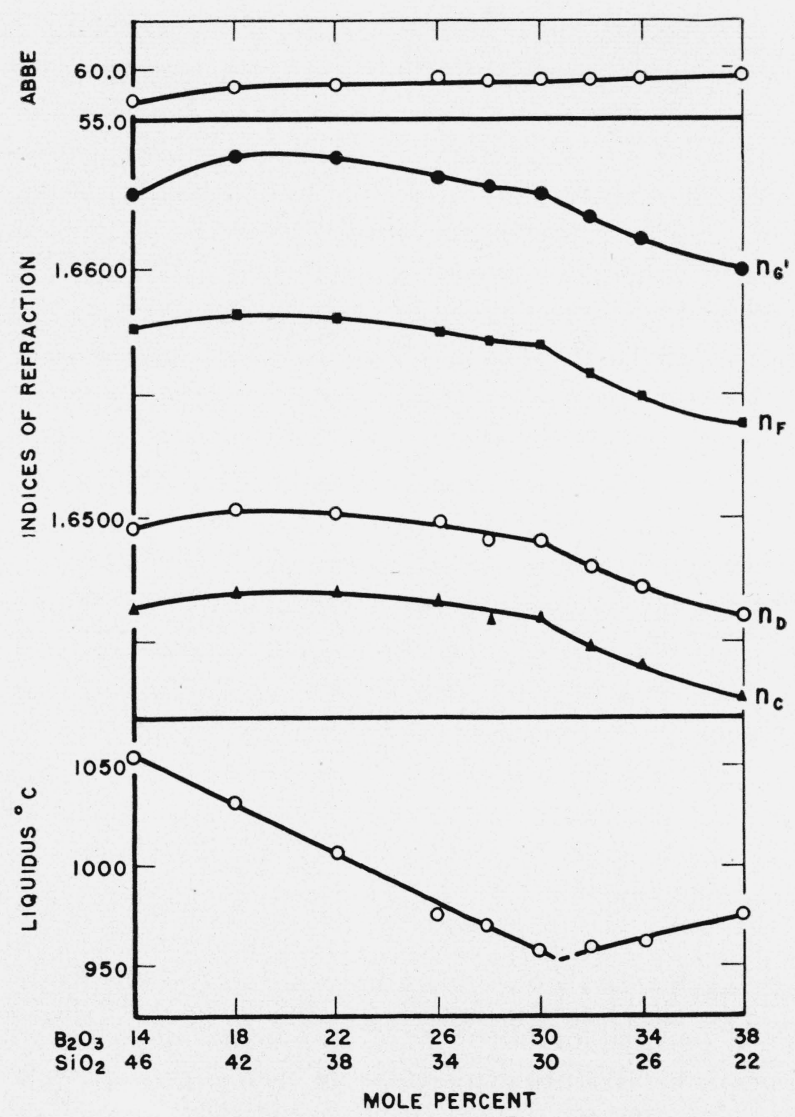

Figure 10. Effect of the substitution of boron oxide for silica in glass 671 on the Abbe value, indices of refraction, and liquidus.

TABLE 11. Series 10. Substitution of boron oxide for silica

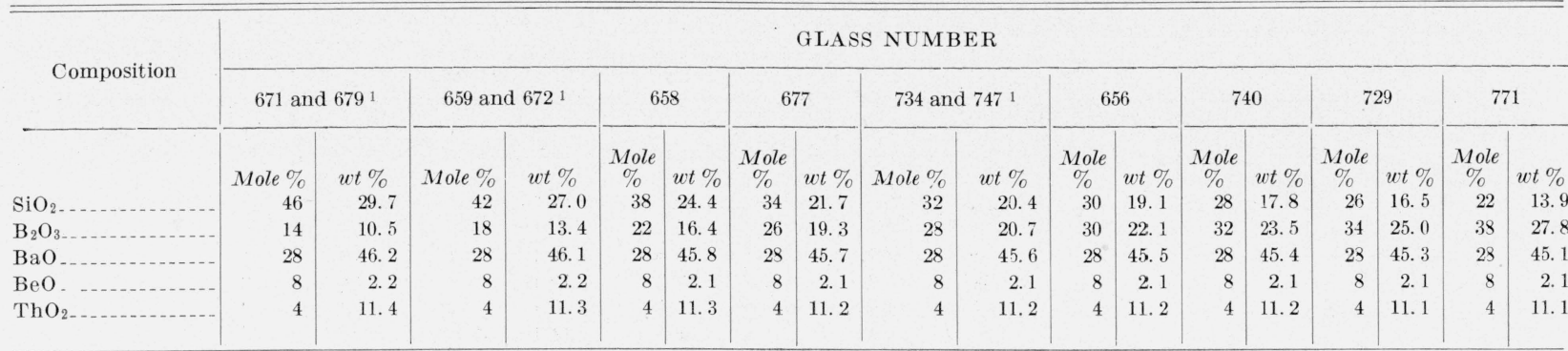

INDEX OF REFRACTION

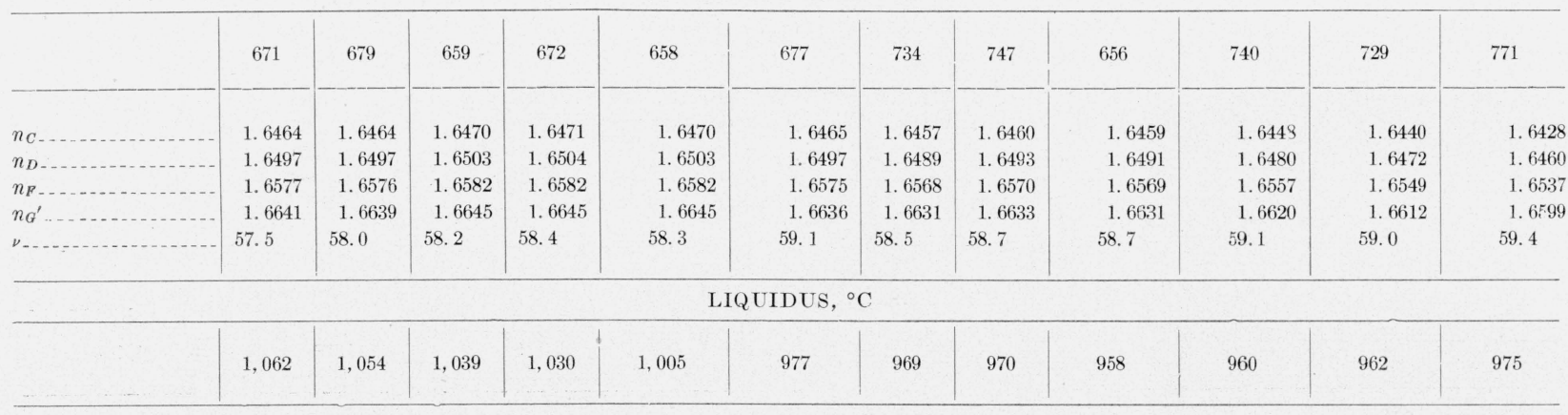

${ }_{1}$ Duplicate batch compositions. 
containing approximately 20 mole percent of boron oxide. A minimum liquidus was found at approximately 30 mole percent of boron oxide. Anisotropic crystals were formed at the liquidus from glasses containing 30 mole percent or less of boron oxide. Glasses containing more than 30 mole percent of boron oxide produced isotropic crystals at the liquidus.

In all the series of melts in which boron oxide was substituted for silica similar anomalous effects on the indices of refraction of the glasses were observed. The maximum index of refraction in each series was found at 18 to 22 mole percent of boron oxide. A similar anomalous effect was observed by English and Turner [3] in a series of $\mathrm{Na}_{2} \mathrm{O}$.$\mathrm{B}_{2} \mathrm{O}_{3} \cdot \mathrm{SiO}_{2}$ glasses containing approximately 20 percent of $\mathrm{Na}_{2} \mathrm{O}$. They found a maximum in the index of refraction curve at approximately 27 mole percent of boron oxide. This series of glasses was repeated under more controlled conditions by Wang and Turner [4]. The melts were made in platinum crucibles, and the glasses were analyzed. They found a maximum in the index-of-refractioncomposition curve at approximately 20 mole percent of boron oxide. In a series of glasses containing alumina, calcium oxide, sodium oxide, potassium oxide, boron oxide, and silica, Turner and Winks [5] observed a maximum at approximately 24 mole percent of boron oxide.

\section{Serviceability and Chemical Durability of Some Glasses Containing Lanthanum Oxide}

When working with new compositions that might be useful as optical glasses, the question of the serviceability or ability of the glasses to maintain a clear polished surface is always of importance. The hygroscopic nature of an optical glass has been proposed as an indicator of its serviceability [6].

Hygroscopicity determinations were made on the glasses from series 4 in which lanthanum oxide was substituted for barium oxide and on three additional glasses containing 12 mole percent of lanthanum oxide. ${ }^{5}$ A number of glasses were exposed at one time. The results in table 12 are grouped to show simultaneous determinations. For purposes of comparison a sample of a borosilicate crown optical glass (BSC 517/645) known to have good serviceability and a sample of a glass of unsatisfactory serviceability ("dish") were in-

\footnotetext{
${ }_{5}^{5}$ Determinations made by Donald Hubbard of this Bureau.
}

cluded. The results indicate that the glasses containing lanthanum oxide are as good as or better than BSC 517/645.

TABLE 12. Hygroscopicity of some glasses containing lanthanum oxide as indicated by exposure to the high humidity obtained from a saturated $\mathrm{CaSO}_{4} \cdot 2 \mathrm{H}_{2} \mathrm{O}$ solution in a closed system ${ }^{1}$

\begin{tabular}{|c|c|c|c|c|c|c|c|}
\hline \multirow{2}{*}{ Glass No. } & \multicolumn{5}{|c|}{ Mole percent of- } & \multicolumn{2}{|c|}{$\begin{array}{l}\text { Water sorbed } \\
\text { after exposure } \\
\text { for- }\end{array}$} \\
\hline & $\mathrm{SiO}_{2}$ & $\mathrm{~B}_{2} \mathrm{O}_{3}$ & $\mathrm{BaO}$ & $\mathrm{BeO}$ & $\mathrm{La}_{2} \mathrm{O}_{3}$ & $1 \mathrm{hr}$ & $2 \mathrm{hr}$ \\
\hline \multicolumn{8}{|c|}{ GROUP A 2} \\
\hline & & & & & & $\mathrm{mg} / \mathrm{cm}^{3}$ & $\mathrm{mg} / \mathrm{cm}^{3}$ \\
\hline $645 \ldots$ & 46 & 14 & 32 & 8 & 0 & 18.6 & 33.3 \\
\hline $675 \ldots \ldots$ & 46 & 14 & 31 & 8 & 1 & 12.3 & 17.9 \\
\hline $646 \ldots \ldots \ldots$ & 46 & 14 & 30 & 8 & 2 & 9.2 & 14.3 \\
\hline $651 \ldots$ & 46 & 14 & 29 & 8 & 3 & 6.8 & 12.5 \\
\hline $673 \ldots \ldots$ & 46 & 14 & 28 & 8 & 4 & 13.8 & 26.3 \\
\hline $676 \ldots$ & 46 & 14 & 27 & 8 & 5 & 10.8 & 20.6 \\
\hline $\mathrm{BSC}^{-517 / 645}$ & -... & $\ldots$ & -- & $\ldots$ &.-- & 17. 0 & 23.6 \\
\hline \multicolumn{8}{|c|}{ GROUP B } \\
\hline $676 \ldots$ & 46 & 14 & 27 & 8 & 5 & 17.0 & 20.6 \\
\hline $647 \ldots \ldots$ & 46 & 14 & 26 & 8 & 6 & 7.1 & 11.5 \\
\hline $649 \ldots$ & 46 & 14 & 24 & 8 & 8 & 3.8 & 11.2 \\
\hline $674 \ldots$ & 46 & 14 & 22 & 8 & 10 & 2. 0 & 6.5 \\
\hline $650 \ldots \ldots$ & 46 & 14 & 20 & 8 & 12 & 3. 6 & 9.6 \\
\hline \multicolumn{8}{|c|}{ GROUP C } \\
\hline $650 \ldots$ & 46 & 14 & 20 & 8 & 12 & 5. 7 & 8.0 \\
\hline $732 \ldots$ & 30 & 30 & 20 & 8 & 12 & 6. 4 & 9.3 \\
\hline 744 & 28 & 28 & 26 & 6 & 12 & 5.3 & 8.4 \\
\hline $745 \ldots$ & 28 & 28 & 24 & 8 & 12 & 5.5 & 8.7 \\
\hline BSC $517 / 645$ & .... & -.. & -.. & $\ldots$ & $\ldots$ & 18.4 & -..- \\
\hline "Dish" ..... & $\ldots$ & $\ldots$ & ... & $\ldots$ & $\ldots$ & $\begin{array}{c}60.6 \\
7=0\end{array}$ & 117.0 \\
\hline
\end{tabular}

1 Determinations made by Donald Hubbard of this Bureau.

2 Groups indicate samples exposed at the same time.

To obtain an indication of the chemical durability of glasses containing lanthanum oxide, polished samples of four glasses containing 12 mole percent of lanthanum oxide were partially immersed in Britton universal buffer at $\mathrm{pH}$ values from 2 to 12 and in 5-percent sodium hydroxide solution for 6 hours at $80^{\circ} \mathrm{C}$, and the amount of attack was measured by an interferometer method [7]. The results are given in table 13, which also includes for comparison the data on a BSC 517/645 and a light barium crown optical glass (LBC 540/574). The glasses containing lanthanum oxide appeared to be slightly less acid-resistant and considerably more alkali-resistant than the typical crown optical glasses. 
TABLE 13. Attack values on four glasses containing 12 mole percent lanthanum oxide exposed for $6 \mathrm{hr}$ at $80^{\circ} \mathrm{C}$ to Britton universal buffer covering $\mathrm{pH}$ range 2.0 to 12.0 and to 5-percent sodium hydroxide solution as determined by an interferometer method 1

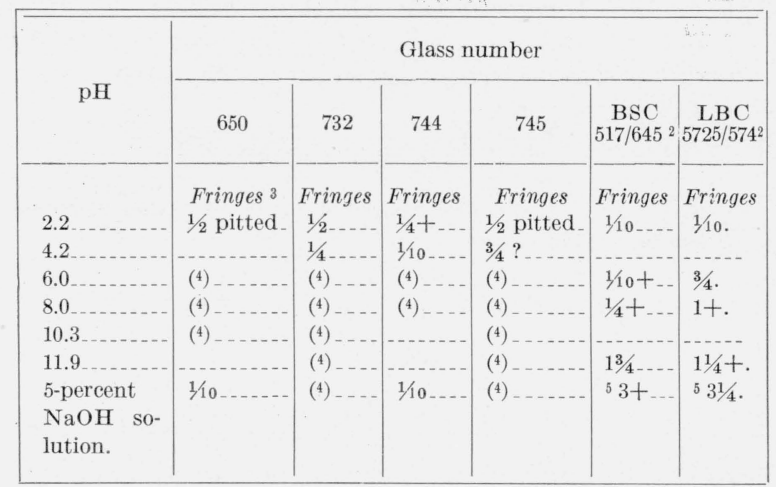

1 Determinations made by Donald Hubbard of this Bureau.

2 BSC 517/645 and LBC 5725/574 are borosilicate crown and light barium crown optical glasses, respectively.

3 One fringe equals approximately 0.29 micron. 4 Not detectable.

${ }_{5}^{5}$ Exposed for $3 \mathrm{hr}$; the attack for 6-hr exposure should be approximately twice the reported values.

\section{Conclusions}

1. The substitution of beryllium oxide for barium oxide on a mole-for-mole basis lowered the index of refraction and increased the Abbe value. When beryllium oxide was substituted for silica, the index of refraction was increased, and the Abbe value was only slightly changed. When less than 6 to 8 mole percent of beryllium oxide was substituted for barium oxide or silica, the liquidus temperature was lowered. Greater amounts of beryllium oxide raised the liquidus temperature and increased the tendency of the glass to crystallize.

2. Substituting up to 26 mole percent of calcium oxide for barium oxide on a mole-formole basis markedly. aided the fining of the glass, but the index of refraction was lowered and the Abbe value was increased.

3. The substitution of lanthanum oxide for barium oxide on a mole-for-mole basis produced a large increase in the index of refraction and a decrease in Abbe value. The increase in index of refraction averaged 0.0056 per mole percent substituted. The substitution of more than 6 mole percent produced a large increase in liquidus temperature.

4. The substitution of thorium oxide for barium oxide on a mole-for-mole basis produced an increase in the index of refraction and a decrease in Abbe value. The increase in index of refrac- tion averaged 0.0028 per mole percent substituted The substitution of more than 4 mole percent produced a very large increase in liquidus temperature.

5. The substitution of boron oxide for silica produced an increase in Abbe value and an anomalous effect on the index of refraction. As the boron oxide was increased, the index of refraction increased to a maximum near 22 mole percent of boron oxide. Increasing the boron oxide content of the glasses usually lowered the liquidus temperature; the glasses containing lanthanum oxide were exceptions to this statement.

6. Discontinuities in the liquidus-composition curve and the index of refraction curves for each series were found at approximately the same composition. These discontinuities, which were accompanied by a change in the primary phase at the liquidus temperature, indicated a change in the arrangement of the atoms in the glass phase.

7. The possibility of producing optical glasses with indices of refraction of 1.71 or higher with Abbe values above 50.0 was indicated.

8. Glasses containing lanthanum oxide exhibited very low hygroscopicity, which indicates that they will maintain good polished surfaces under normal conditions of service. These glasses appeared to offer unusually high resistance to the attack of alkaline solutions.

9. Experimental glasses have been made that markedly depart from the linear relationship between index of refraction and Abbe value that prevails in ordinary optical glasses. The field of known optical glasses has been extended in a very desirable direction from the point of view of optical instrument design.

\section{References}

[1] U. S. Patents $1,943,051 ; 2,150,694 ; 2,206,081 ; 2,241$,$249 ; 2,297,453 ; 2,406,580$; Gorden F. Brewster, Norbert J. Kreidl, and Tyler G. Pett, J. Soc. Glass Tech. 31, 153 (1947)

[2] W. B. Silverman, J. Am. Ceram. Soc. 2?, 378 (1939).

[3] S. English and W. E. S. Turner, J. Soc. Glass Tech. 7, 155 (1923).

[4] T. H. Wang and W. E. S. Turner, J. Soc. Glass Tech. 29, 390 (1945).

[5] W. E. S. Turner and Francis Winks, J. Soc. Glass Tech. 9, 389 (1925).

[6] Donald Hubbard, J. Research NBS 36, 365 (1946) RP1706.

[7] Donald Hubbard and Edgar H. Hamilton, J. Research NBS 27, 143 (1941) RP1409.

Washington, November 12, 1947. 